\title{
Territorios comunes: los lazos intrincados de la literatura y el cine contemporáneo argentino
}

\author{
Common territories: the intricate links between \\ contemporary Argentine literature and cinema \\ Territórios comuns. Os laços intrincados da literatura \\ e o cinema contemporâneo argentino
}

\section{Marcos Zangrandi}

CONICET/UNIVERSIDAD DE BUENOS AIRES, ARGENTINA

Investigador de CONICET. Pertenece al Instituto de Literatura

Hispanoamericana (Universidad de Buenos Aires, Argentina). Es doctor en Ciencias Sociales (UBA). Editó los libros La Ciudad Viva (GCBA, 2009) y Policiales por encargo (con David Viñas, EBN, 2012), los cuales se desprenden de investigaciones en las que participó. En 2016 publicó el libro Familias póstumas. Literatura argentina, fuego, peronismo (Godot). Sus últimas publicaciones son: "Julio Cortázar e o cinema. Afinidades, mal-estares e desencontros" (Revista da Biblioteca Mario de Andrade, 2016) e "Imágenes en el abismo. Antín, Cortázar e Intimidad de los parques" (Revista Chilena de Literatura, 2016). Correo electrónico: marcoszangrandi@gmail.com

\footnotetext{
Artículo de investigación

Este artículo forma parte de una investigación del autor enmarcada en el proyecto "Lenguajes convergentes. Cineastas y escritores en la transformación del cine y de la literatura", afiliado a CONICET y al Instituto de Literatura Hispanoamericana de la Universidad de Buenos Aires.

Documento accesible en línea desde la siguiente dirección: http://revistas.javeriana.edu.co 


\section{Resumen}

Este texto estudia las relaciones múltiples entre el cine y la literatura argentinos contemporáneos desde un enfoque sociocultural y desde las estéticas que se desprenden, en un sentido amplio, entre ambos espacios. El artículo advierte que las acciones en el campo tienden a constituir un territorio común, en el que, progresivamente, se desarma la idea del pasaje, de la presencia del escritor en la instancia de escritura y la dirección obligada literatura/ cine. En el plano estético, el lazo entre ambos es más complejo y paradójico, en tanto se afirma que la literatura y el cine trabajan complementándose, cruzándose e incorporando procedimientos impropios.

\section{Palabras clave: cine} argentino; literatura argentina; transposición; estética cinematográfica; colaboración

\section{Abstract}

This paper studies the multiple relations between the cinema and the contemporary argentine literature from the sociocultural point of view and from the aesthetics that emerge, in a broad sense, between both spaces. This text warns that actions in the field tend to constitute a common territory, in which, progressively, disarms the idea of the passage, the presence of the writer in the process of writing, and the obligatory direction literature/films. On the aesthetic level, the bond between both is more complex and paradoxical. The relationship is affirmed as the literature and the cinema work complementing each other, crossing each other and incorporating improper elements.

Keywords: argentine cinema; Argentine literature; transposition; cinema aesthetics; collaboration

\section{Resumo}

Este texto estuda as relações múltiplas entre o cinema e a literatura argentinos contemporâneos desde um enfoque sociocultural e desde as estéticas que se desprendem, em um sentido amplo, entre ambos os espaços. $\mathrm{O}$ artigo adverte que as ações no campo tendem a constituir um território comum, em que, progressivamente, é desarmada a ideia da passagem, da presença do escritor na instancia de escritura e a direção obrigada literatura/ cinema. No plano estético, o laço entre os dois é mais complexo e paradoxal, em quanto literatura e cinema trabalham se complementando, entrecruzando e incorporando procedimentos impróprios.

Palavras-chave: cinema argentino; literatura argentina; transposição; estética cinematográfica; colaboração

RECIBIDO: 2 DE MARZO DE 2017. ACEPTADO: 1 DE NOVIEMBRE DE 2017. DISPONIBLE EN LÍNEA: 28 DE DICIEMBRE DE 2018

\section{Cómo citar este artículo:}

Zangrandi, Marcos. "Territorios comunes: los lazos intrincados de la literatura y el cine contemporáneo argentino". Cuadernos de Literatura 22.44 (2018): 140-158. https://doi.org/10.11144/Javeriana.cl22-44.tcli 
En AdÁn Buenosayres. La película (2016), el director Juan Villegas examina el proyecto, nunca realizado, de llevar la novela de Leopoldo Marechal al cine. Recrea incluso algunas escenas de aquel libro como forma de "exorcismo" o, tal vez, como modo de sobrevolar una imposibilidad. Dificultad primordial que no solo se habría asentado en aquel intento fallido del director Manuel Antín, sino que puede considerarse como una propiedad de las relaciones entre el cine y la literatura. Independientemente del objeto de la película (que conduce hacia los obstáculos políticos y culturales de principios de los años setenta en Argentina), las reflexiones del documental echan luz sobre un rodeo recurrente y espinoso del cine argentino en torno a la literatura, a la vez que dibujan una elipse entre una primera modernización del cine argentino de la década de 1960 (en la que Antín participó) con el cine argentino que se comenzó a realizar a partir de la década de 199o. Las preguntas que hace Juan Villegas permiten pensar la relación cine/literatura contemporáneos como un mecanismo en el que ambos territorios, antes que delimitar una frontera, parecen vincularse abriendo y disputando bastiones estéticos y sociológicos. ${ }^{1}$

La dificultad, como punto de partida, señala la talla de la complejidad de los vínculos que se tejen entre las maquinarias del cine y de la literatura, y que, en particular, caracterizan tanto a la nueva literatura como al nuevo cine argentinos recientes. Complejidad, porque no se trata de un problema de pasajes entre la letra y la imagen -que deriva hacia problemas de la transposición (o alguna otra imagen de traslación) o hacia cuestiones técnicas-. ${ }^{2}$ Mucho menos un tema de legitimidad, en una instancia en la que el cine, en sus múltiples dimensiones, ya tiene un estatuto cultural y teórico sobradamente constituido frente a cualquier planteo "originario" de la literatura (y, bajo esta mitificación, frente a la idea de un cine dependiente de fuentes literarias). Diferenciado de estos aspectos, el panorama de la producción contemporánea cuestiona la imaginación de dos polos

1 Lo interesante de este documental de Villegas no es un objeto (Leopoldo Marechal y la novela Adán Buenosayres), sino un proyecto frustrado de alianza entre cine y literatura. Cabe destacar que hay numerosas películas-ensayos dedicadas a escritores argentinos realizadas en las últimas décadas, entre otras Gombrowicz o la seducción (1986, Alberto Fischerman), Cortázar (1994, Tristán Bauer), Rosa Patria (2008, Santiago Loza), Ante la ley (2012, Emiliano Jelicié y Pablo Klappenbach) y 327 cuadernos (2015, Andrés di Tella).

2 Sobre la problemática de la transposición, véanse los textos de Sergio Wolf, Ritos de pasaje y de José Luis Sánchez Noriega, De la literatura al cine. 
diferenciados cuya comunicación está codificada y, en cambio, señala la imbricación y organicidad de los lazos entre ambos planos.

El cine argentino que se produjo a partir del nuevo siglo trazó una relación estrecha y múltiple con la literatura a partir de adaptaciones, colaboraciones e innovaciones estéticas compartidas. Piénsese, solo como ejemplos preliminares, en el director Diego Lerman trabajando con los textos de César Aira, en los libros y en las películas de Martín Rejtman, en las varias adaptaciones de las narraciones de Antonio di Benedetto en distintas realizaciones recientes o en los filmes que se realizaron a partir de las novelas de Claudia Piñeiro. Hay, por lo menos, dos caminos inevitables para pensar estos lazos. Por un lado, los modos socioculturales específicos en que el cine y la literatura argentinos han construido sus vínculos en el campo de la cultura. Un aspecto que lleva, necesariamente, a preguntar por el efecto modernizador de esta relación que se produjo en los años 1960 y por los rasgos de aquellas colaboraciones que se proyectan sobre el cine a partir de los años noventa. Un panorama que no solo incluye los cambios de estatutos que las dos zonas han edificado cruzándose, sino a los rasgos que las figuras del cineasta y del escritor adquieren a partir del trazado de ciertos vínculos. El otro camino requiere, en cambio, estudiar las estéticas que se generan a partir de estos lazos, en particular los que forja la emergencia de un nuevo cine (con todo lo que esta fuerza implica) con la literatura. Esto es, examinar los enlaces reversibles, las sinergias estéticas y los espacios de confluencia. Más aún, en los modos en que el cine y la literatura se diferencian y se entrecruzan necesariamente a partir de sus propias materias y de su condición de territorios, al mismo tiempo, divergentes y afines.

\section{El campo: diversificaciones y reversibilidades}

Uno de los puntales de la renovación del cine argentino de los sesenta fue el vínculo estrecho que estableció con la literatura. ${ }^{3}$ En aquellos años, los realizadores más jóvenes buscaron diferenciarse de la figura del guionista o adaptador profesional, propio del sistema de estudios, y, en cambio,

3 Sobre las características del nuevo cine argentino de los años sesenta, ver los volúmenes de Fernando Martín Peña (Generaciones 60/90) y de Claudio España ("Emergencia y tensiones"). Sobre detalles de las colaboraciones de escritores en la historia del cine argentino, véanse los trabajos de Jorge Miguel Couselo ("Literatura argentina") y Mireya Bottone (La literatura argentina). 
incorporaron figuras literarias de renombre en la escritura de los libros cinematográficos. Con esto, el nuevo cine quería no solo tomar distancia de los modos de producción que habían dominado desde las décadas anteriores, asociadas a la producción masiva, sino también ganar el prestigio que provenía del espacio de la literatura. ${ }^{4}$ Narradores notables se integraron a esta propuesta (Jorge L. Borges, Adolfo Bioy Casares, Juan José Manauta, Marco Denevi, Augusto Roa Bastos, Ernesto Sábato y otros) (Bottone La literatura argentina y el cine; Couselo "Literatura argentina y cine nacional"), y hasta incluso se conformaron duplas de trabajo sostenido entre algunos directores y cineastas (Manuel Antín y Julio Cortázar, David Viñas y Fernando Ayala, Beatriz Guido y Leopoldo Torre Nilsson, que fue la asociación que generó mayor cantidad de trabajos). ${ }^{5}$ De este modo, los escritores obtenían más espacios en otro terreno sociocultural y se plegaban a un medio de masas progresivamente reconocido, en el marco de los debates que fisuraban el campo de la literatura tal como se había constituido hasta entonces (Terán Nuestros años sesentas; Cernadas "Notas sobre la desintegración"). Se trató de un replanteo de la asociación entre el cine y la literatura en el marco de las transformaciones de los dos ámbitos; aquellas colaboraciones, de carácter necesario -se requería la

4 No se pueden entender estos cambios en el sistema de producción cinematográfica sin tomar en cuenta la crisis económica y creativa de los estudios durante la década de 1950 (Posadas "La caída de los estudios"). En 1955, el nuevo gobierno militar terminó de liquidar el sistema de estudios y promovió una ley de cine que se puso en marcha en 1957. Si bien la nueva norma tenía como fin promover una renovación de la producción audiovisual, su sistema de premios terminó favoreciendo a las grandes productoras. El nuevo cine argentino de los años 1960, en realidad, se produjo con pocos recursos y contó con escaso apoyo del estado. Claudio España ("Emergencia y tensiones en el cine argentino") señala que ya desde los años cuarenta el cine argentino producía renovaciones formales y narrativas.

5 Manuel Antín dirigió La cifra impar (1961) sobre el cuento "Cartas de mamá" de Julio Cortázar. Este no tuvo participación en este filme, pero sí en la escritura de los guiones de otros dos filmes de Antín: Circe (1963) e Intimidad de los parques (1964) (Oubiña Manuel Antín; Zangrandi "Imágenes en el abismo"). David Viñas y Fernando Ayala trabajaron en colaboración en los guiones de El jefe (1958) y El candidato (1959) (Rapallo Fernando Ayala). Una vez disuelta esta sociedad, Viñas escribió junto a José Martínez Suárez en Dar la cara (1962). Son muchas las películas que se desprendieron de la dupla Guido-Torre Nilsson durante estos años; es imprescindible destacar La casa del ángel (1956), La caída (1958), El secuestrador (1958), La mano en la trampa (1960) y La terraza (1962) (Peña Leopoldo Torre Nilsson). 
presencia del escritor y del director en la elaboración del filme-, buscaban, de manera duplicada, tanto una mayor legitimación del cine dentro de la cultura, como una respuesta a las transformaciones que exigía la literatura de los años sesenta (Zangrandi "Imágenes en el abismo"). Más aún, esta confluencia se convirtió en un catalizador de la modernización del cine; y a la vez, el nuevo cine de los sesenta tomó recursos estéticos y narrativos abiertos por la literatura (evidente, por ejemplo, en películas como Circe y La mano en la trampa) y los incorporó a la pantalla grande, teniendo en cuenta, por supuesto, la especificidad propia de la imagen y del filme (España Cine argentino; Peña Leopoldo Torre Nilsson).

A partir de los años noventa, el cine argentino invoca al sistema de la literatura como espacio que impulsa una renovación del cine, y, en este sentido, sus películas parecen atravesadas por ejes estéticos cercanos a los de la literatura contemporánea. Pero el modo de asociación y la dimensión que cada territorio tiene ha cambiado respecto de aquellos de los sesenta. El rasgo más evidente, en este sentido, es que, a pesar de los numerosos textos llevados a la pantalla grande, en ninguno de los casos hay interés por una colaboración presencial y efectiva entre directores y cineastas, tal como había sucedido algunas décadas atrás. Aquel requerimiento de la figura presente del narrador, que rubricaba o hacía una venia a la escritura del libro cinematográfico, se desvanece -piénsese, por ejemplo, el contraste con la imagen de Cortázar corrigiendo y rectificando las versiones del guion de Intimidad de los parques [1965] que le enviaba Manuel Antín-. No sucumbe la sociedad literatura/cine; lo que se deshace es la mano del narrador en la instancia de escritura cinematográfica y, de acuerdo a esto, el estatuto de esa necesidad se vuelve contingente. ${ }^{6}$ Detrás de este desvanecimiento, hay que advertir un cambio mayor: la disipación de la literatura como fuente de un cine que, bajo esta nueva configuración, sería una relación endeble (y desde allí, la cultura letrada respecto de la cultura de masas). Desde esta perspectiva, el cine juega con un formato de reversibilidad y diversificación de las relaciones literatura/escritura/cine.

6 Una excepción reciente (y parcial) es la labor de Leonardo Oyola para la serie de tevé Nafta Súper (2016), proyecto en el que colaboró como coguionista. La serie es una secuela del filme Kryptonita (2015, Nicanor Loreti), que se basa en la novela homónima de Oyola. El narrador, sin embargo, no trabajó en el libro de la película, que fue escrito por Camilo del Cabo y Nicanor Loreti. 
Si no es en esa presencia efectiva del escritor en la instancia de la escritura, en cambio, la sociedad cine/literatura se queda con la incorporación del nombre de la figura literaria en el filme, nombre que agrega valor a los filmes y a sus realizadores. Es inevitable, por ejemplo, considerar el efecto claramente impulsor del nombre César Aira, una de las figuras centrales de la literatura argentina contemporánea, sobre las películas Tan de repente (2003) y La guerra de los gimnasios (2005), que a la vez recae sobre su director, Diego Lerman, ${ }^{7}$ aunque en ninguna de esas películas el escritor haya intervenido directa o indirectamente. Puede pensarse un impacto similar respecto de Antonio Di Benedetto y los filmes Los suicidas (2005, Juan Villegas), Aballay (2010, Fernando Spiner) y Zama (2017, Lucrecia Martel); de Silvina Ocampo sobre Cornelia frente al espejo (2012, Daniel Rosenfeld); de Juan José Saer sobre El limonero real (2016, Gustavo Fontán), de Humberto Costantini sobre La larga noche de Francisco Sanctis (2016, Francisco Márquez y Andrea Testa) o de Martín Kohan sobre La mirada invisible (2010, Diego Lerman). Esta lista permite, asimismo, visualizar un efecto en reversa; esto es, examinar cómo, a partir de estos filmes se producen nuevas circulaciones, impulsos y relecturas dentro del campo de la literatura argentina. ${ }^{8}$

A propósito de La mirada invisible, es interesante que Kohan (autor de la novela Ciencias morales de la que se alimenta el guion) haya participado no como escritor sino con un bolo (interpreta a un vendedor de discos). A esta curiosidad se agregan otras: Lerman, reconocido director de actores, intentó hacer actuar a César Aira en La guerra de los gimnasios; el narrador Alberto Laiseca protagonizó El artista (2009, Gastón Duprat y Mariano Cohn). En el cine argentino contemporáneo -parece señalarse-, el escritor, en tanto sujeto físico, se despega de la autoridad de la escritura y de la gestión narrativa; su imagen es, en cambio, el objeto de la cámara,

7 El guion de Tan de repente (2003) está basado en la novela La prueba (1992) de César Aira. Ya en 1999 el mismo director había realizado un corto con el mismo nombre de esta novela. El cortometraje La guerra de los gimnasios (2005) es una adaptación parcial de la novela homónima de Aira (1993).

8 A esta lista, puede agregarse la figura orbitante de Ricardo Piglia durante los años noventa. Entre otras colaboraciones, coescribió el guion de La sonámbula (Fernando Spiner, 1997), film que en su planteo ficcional dialoga con la tradición de la literatura fantástica argentina (principalmente con Bioy Casares, Borges y Cortázar). La adaptación de su novela Plata quemada fue llevada al cine en 2000 por Marcelo Piñeyro, a partir del guion elaborado por este director y el narrador Marcelo Figueras. 
un fetiche de la pantalla o una curiosidad. He aquí una gran diferencia con las colaboraciones de los sesenta: es difícil imaginar como actores (y no como autores) a Borges, a Cortázar, a Viñas o incluso a la histriónica Beatriz Guido.

La presencia del escritor está desplazada, pero también el lugar fundante que tenía el texto literario sobre el cinematográfico. Dice Lerman respecto de Tan de repente: "Trabajé con esa novela de Aira como un punto de partida, y no con la idea de respetar toda la novela [...] para mí adaptar es traicionar desde el primer momento para tomar sólo lo que a mí me interesa" (Bernini et al. 164). Efectivamente, la película solo toma las situaciones y las acciones iniciales de La prueba (la invitación y la charla entre Lenin, Mao y Marcia), pero después se traslada hacia otras líneas narrativas y estéticas, sin asumir el recorrido de la novela de Aira. Este mismo gesto, sin la gravedad de la traición, marca una modalidad de trabajo: se apela a la literatura, pero se toma una distancia necesaria respecto de ella. "Después de la primera versión, sigo rescribiendo, pero ya no reviso la novela, sobre todo porque la segunda mitad del guion se despegó mucho de la novela" (Bernini et al. 165), comenta Villegas sobre la transposición de la novela Los suicidas de Di Benedetto. Y respecto de Fabián Casas, autor de la novela Ocio (2008): "quedó contento porque la película no se parecía mucho a la novela" (2016). ${ }^{9}$ La transposición de Ocio, en efecto, solo recupera los personajes y los escenarios de Casas, pero el argumento dista visiblemente respecto del planteo narrativo del libro. ${ }^{10}$ La relación de la transposición para Rejtman es aún más libre: "El guion de Silvia Prieto se basó libremente en una novela inconclusa de Valeria Paván, que trabaja de moza acá (Bar 2 Mundos). Ella estaba escribiendo una novela y me la pasó hace unos dos años [...] transcurría gran parte en un bar y la protagonista era una moza de un bar. Tomé el personaje de esta novela que estaba inconclusa y la convertí en Silvia Prieto. Después el guion derivó para un lado completamente diferente a lo que es la novela" (Guerschuny y Udenio 34). Lejos parece ubicarse la devoción de Manuel Antín (quien llegó a repartir ejemplares de Don Segundo Sombra durante

9 Cabe destacar que Fabián Casas no intervino en el film Ocio de Villegas. Sí, en cambio, colaboró como guionista en la película fauja, de Lisandro Alonso (2014).

1o La relación entre el filme y la novela Ocio permite pensar en la hipótesis de una relación más abierta entre cine y literatura. Sin considerar una instancia de "fuente", el texto y la película serían episodios de una gran novela no escrita. 
el rodaje del filme homónimo de 1969) y la actitud respetuosa de Leopoldo Torre Nilsson hacia los títulos que adaptó (por ejemplo, Martín Fierro [1968], Los siete locos [1973] y La guerra del cerdo [1975]). Hay un marcado desinterés por la literalidad de parte de los cineastas del cine más reciente, pero también un desprejuicio de parte de los escritores respecto de que sus textos, sin su intervención directa, sean modificados, leídos de forma heterodoxa o desnaturalizados por una película. No hay malestares, en este sentido, acerca de la fidelidad de alguna de estas películas respecto de su versión literaria y las expectativas están emplazadas, en cambio, para que el filme realice su recorrido con la materia y los procedimientos propiamente cinematográficos.

Por su centralidad y por su particularidad, el caso Martín Rejtman merece ser visto como sintomático (aunque su caso sea, a la vez, único) de las transformaciones contemporáneas. A partir de Rapado (1992) se convirtió en uno de los directores centrales del nuevo cine y uno de los principales referentes de la renovación durante los años noventa (Aguilar Otros mundos; Andermann El nuevo cine argentino). De manera confluyente, Rejtman ha forjado una carrera como narrador (Rapado, 1992; Velcro y yo, 1996; Literatura y otros cuentos, 2005; Tres cuentos, 2012) reconocida dentro del campo de la literatura (Speranza "Por un realismo idiota"; "Tres cuentos). ${ }^{11}$ Lo interesante de los trabajos de Rejtman es la dimensión contigua como escritor y como realizador de cine. No se podría afirmar que adapta sus propios cuentos (el relato "Rapado", a la inversa de la forma habitual de las adaptaciones, es apenas un esbozo frente a la fecundidad narrativa de la película), ni que sus libros son derivas de sus filmes, sino que ambos, películas y textos, circulan bifurcados y progresivamente potenciados, a la par de su figura. ${ }^{12}$

En el cine de los sesenta había duplicaciones de los roles y de los estatutos de la literatura y del cine. Después de Rejtman -en tanto hito-, hay expansión y superposición de esos mismos espacios: se expande la superficie de trabajo del cineasta (ya no hay un compartimento que delimite

11 No puede dejar de señalarse el caso de Edgardo Cozarinsky como figura que ha buscado, a lo largo de su carrera y de manera sostenida, escribir y filmar. Entre otras, vale destacar sus películas Puntos suspensivos o Esperando a los bárbaros (1971), Guerreros y cautivas (1990) y Ronda nocturna (2005).

12 El producto más vinculado es el que Rejtman elaboró junto a Federico León: Entrenamiento elemental para actores. La película se estrenó en 2009 y el libro, con el mismo nombre, se publicó en 2012. 
su tarea) y, a la vez, las capacidades y las posibilidades del cine. Es posible afirmar que, si en el formato de cine de estudios y en el moderno la relación entre el cine y la literatura argentinos se mantenía como traslación o como traducción siempre en una misma dirección (de la literatura hacia el cine), el lazo contemporáneo, una vez que la literatura y el escritor se han desvanecido como punto de partida y como fundamento, se acerca a un territorio progresivamente común, en el que las direcciones y las acciones, liberadas de límites necesarios, se expanden y se reconvierten.

\section{Las estéticas: un cine impropio}

Si desde el punto de vista sociocultural el cine y la literatura tienden a trabajar en una zona común -aunque no indiferenciada-, en el plano estético, el vínculo se vuelve más intrincado, de acuerdo con la acción continua y conjunta en que películas y textos operan, se alían y se diferencian. Para Jacques Rancière (El reparto de lo sensible) el cine y la literatura extenderían nuevas sensibilidades, posibilitarían nuevos espacios, permitirían nuevas acciones. ${ }^{13}$ Pero su acción estética no es idéntica. El cine se formula siempre como posterior a la literatura; esto es, como un después y a partir de la operación político-estética de la literatura. De acuerdo con su conformación sensible y con sus dominios, el cine se conforma

13 Para Rancière, el Régimen Estético de las Artes formula una emancipación de las reglas policiales (géneros, métricas, corrientes, estilos, etc.) que legislaban la producción y el acceso a las artes; no hay una poética o un conjunto de normas que permitan precisar el objeto estético, sino múltiples. El conjunto de las artes bajo este régimen está signado por la mezcla; más aún, requieren del cruce, de la impureza, como una frontera inestable y necesariamente cambiante (Rancière Las distancias del cine). El desarrollo de la literatura a lo largo del siglo XIX significó una verdadera revolución. Entre otras razones, por la mixtura de temas y formas elevados con aspectos vulgares, cotidianos o triviales, en contra de la normativización representativa de las artes. Luego, y a partir de la preponderancia de la palabra escrita sobre la viva, la literatura aparece como una zona atiborrada de signos mudos y a la vez parlantes, equiparados, de manera tal que "todo cae en la indiferencia igualitaria, pero simultáneamente toda una sociedad puede leerse en su verdad gracias a los fósiles que descarta sin cesar en los bajos fondos" (Rancière, Política de la literatura 33). A ello, la literatura aporta una nueva forma de tratamiento y de comprensión del tiempo, un modo secuencial novedoso conformado por bloques de tiempo presente, un rasgo ausente en la narrativa anterior al siglo XIX. Con estos y otros aspectos, la literatura, antes que un conjunto reglado de signos, es "una manera de construir el mundo mismo donde pueden ocurrir historias, asociarse acontecimientos, desplegarse apariencias" (Rancière, Las distancias del cine 19). 
entonces como un arte contrariado; solo de esta manera puede llevar a cabo su proyecto emancipatorio (Rancière La fábula cinematográfica). ${ }^{14}$ Es siempre un espacio impropio, impuro, paradójico; es ese gesto, crítico y contrariado, el que le permite potenciar su fuerza estética. De este modo, la relación entre el cine y la literatura se configura mucho más que un asunto de travesía o de traducción entre dos polos. Se trata, en cambio, de dos engranajes que trabajan de manera invertida y complementaria; ambos se requieren y se repelen al mismo tiempo.

Estas nociones de Rancière permiten esclarecer algunos de los vínculos estéticos entre el cine y la literatura como están planteados en el cine argentino contemporáneo. Por ejemplo, el que se traza entre las narraciones de César Aira y las películas de Diego Lerman. El tempo dramático de la novela La prueba se acelera progresivamente desde el recorrido por las calles de Flores (cuya descripción móvil bien puede pensarse como un traveling), se detiene en una larga conversación y una narración entre los tres personajes principales (Marcia, Mao y Lenin), y explota, finalmente, en un desenfreno delirante de acciones en un supermercado, que incluye decapitaciones, incendios y cuerpos aplastados. Un procedimiento frecuente en este narrador; se trataría de una "poética de la acción", como la define Sandra Contreras. La literatura de Aira, señala esta crítica, "fluye a toda velocidad para precipitarse, siempre en un salto hacia la Acción como hacia una dimensión en la que todo se transforma de un modo radical: tiene, podría decirse, en esa precipitación su nudo, su punto de inflexión, su punto de fuga" (294). Uno de los aspectos notables de los libros de Aira es la sucesión continua (a veces, abarrotada) de acciones, frecuentemente insólitas o delirantes, camino, in crescendo, hacia un escenario catastrófico. Con ello los textos rompen el andamiaje verosímil, retorciendo, exprimiendo las posibilidades de la ficción para hacer emerger otra realidad, puramente literaria.

14 En La fábula cinematográfica (2005), Jacques Rancière señala que el cine aparece luego de la desfiguración romántica de las historias (esto es, después de una conquista estética de la literatura), pero se vale de esos mismos recursos para restaurar la mímesis clásica. La literatura abrió un territorio visual; el cine, en cambio, invierte esta estrategia, haciendo de la palabra uno de sus recursos dilectos: "La adición literaria de la imagen era una sustracción de sentido. El cine no puede recuperar esa capacidad por su cuenta sin antes invertir el juego, ahondando en lo visible mediante la palabra" (Rancière, La fábula cinematográfica 24). 
La película Tan de repente trabaja en un sentido evidentemente distinto de la novela. A la narración no le interesa esa velocidad que conduce a una explosión de la realidad, tan propia de las novelas de Aira; por el contrario, elige bajar la velocidad, decrecer, desenhebrar la tensión. La primera proposición (“¿Querés coger?"), en la película no es sino un disparador de un género, la road movie: la pantalla se llena de imágenes fugaces de la ruta, de los transportes, de restaurantes de paso, de mar, de personajes fortuitos y extraños. Otro hecho, azaroso y sin explicación, la caída y muerte de un paracaidista, tuerce la narración hacia la comedia dramática. Esto es, La prueba, acumula acciones hacia un final espectacular; Tan de repente, en cambio, opta por un registro realista, por los géneros constituidos en el cine, por planos convencionales, por profundizar aspectos psicológicos de los personajes, por un ritmo cada vez más lento. Parece ir en contra del plan estético de la novela.

Y sin embargo Tan de repente funciona. No está en falta ni es deudora de la novela. Toma los personajes y unas acciones de Aira para poner en funcionamiento la película, cuya construcción está enlazada con las estéticas del nuevo cine, predominantemente realistas. ${ }^{15}$ Elige quedarse con un solo aspecto de la literatura de Aira: el impacto decisivo del azar (la irrupción de las punks; la imagen inexplicable del paracaidista que pronuncia el nombre de una mujer desconocida), que actúa sobre la narración, sobre la puesta en escena y sobre la concepción cinematográfica. Y es aquí, en este punto aparentemente insignificante, que cine y literatura se articulan en un plano más profundo. A partir la incorporación de ese azar, la incursión

15 El nuevo cine argentino nace con una vocación realista. No quiere ser alegoría, sátira ni pedagogía (caracteres del cine previo), sino, antes que nada, un estado del mundo. No busca la verosimilitud, sino en un registro, que, como lo señala Gonzalo Aguilar, tiene la capacidad de "rozar nuestra experiencia con lo real" (37). La cámara y el lenguaje buscan este borde de roce, de contigüidad, cercana al documental -de allí el apogeo de este género en la producción de las últimas décadas- y un registro crudo, no codificado en numerosas películas de ficción, desde Pizza, birra, faso (1997, Bruno Stagnaro y Adrián Caetano) a El estudiante (2011, Santiago Mitre). Este espectro realista se convierte en la línea estética dominante. Las producciones pudieron incorporarla o resistirse, pero pueden dejar de definirse a partir de ella. De hecho, los directores de ficción que no se pliegan a ella (Esteban Sapir, Diego Lerman, Juan Villegas, Martín Rejtman, Ezequiel Acuña) han sido llamados "los no realistas", según el término acuñado por Silvia Schwarzböck ("Los no realistas"), en contraposición con una oleada "realista" (Pablo Trapero, Bruno Stagnaro, Adrián Caetano). 
en los géneros (la comedia dramática, la road movie), no esté naturalizada, porque su lógica reglada está asediada por acción de lo imprevisible.

Diego Lerman trabajó nuevamente con un texto de Aira en La guerra de los gimnasios (2004). A diferencia de Tan de repente, la película buscaba acercarse con mayor fidelidad, tanto en la puesta en escena como en la narración, a la propuesta delirante y fantástica de la novela. El resultado fue un filme breve que desarrolla, en términos argumentales, solo el inicio del conflicto. Nunca llega el crescendo de acciones, ni al final espectacular del libro. Parece, más bien, un capítulo inicial de una narración que se desarrollará en el futuro o, acaso, un ejercicio de experimentación con un género al que hay que traicionar necesariamente. ${ }^{16}$ Independientemente de las condiciones de producción y de las intenciones de aquel momento, el filme pone de manifiesto la dificultad -0 , tal vez, la renuncia- de llevar a Aira a la pantalla. O, más aún, de los obstáculos que formula el NCA, en tanto proyecto contemporáneo de renovación del cine, de adaptar en términos convencionales una novela a la pantalla. En este sentido, la película La guerra de los gimnasios, en su condición de fragmento de una totalidad no realizable, parece avalar la hipótesis de una construcción contrariada y, a la vez, congruente en el plano estético en el que se enlazan la literatura y el cine.

Martín Rejtman se ha constituido como una figura doble, que actúa en una zona común, en la que pueden encontrarse inmediaciones entre narraciones, imágenes, personajes, acciones, tempos. Pero, aun considerando esos aspectos convergentes y la contigüidad entre el cineasta y el escritor, no podría hablarse de un lazo transparente entre las narraciones escritas y los filmes de Rejtman, ya que "trabajan" diferenciados. ${ }^{17}$ Los relatos

16 Estas son las palabras que utilizó Lerman para describir el cortometraje: "La guerra de los gimnasios es una pequeña fábula sobre la guerra. Una experimentación personal en el género fantástico. Me interesaba sobre todo transitar el género para corromperlo. Este guion es una libre adaptación de la alucinógena novela de César Aira mezclada con anécdotas personales de la etapa en la cual trabajé de "Extra". Yo lo había escrito antes de Tan de repente (2002) y casi conjuntamente con el cortometraje La prueba (1999), tenía como objetivo ser presentado en Historias Breves, pero su extensa duración no lo permitió en su momento, por lo que quedó archivado para ser retomado cinco años después con una vigencia mucho más actual que en la de aquel entonces" (Malba.cine 3).

17 La superficialidad de la composición de los planos (en contra de la ilusión realista de la imagen y de la profundidad de campo), el sorteo del fuera de campo, la sonoridad y el ritmo del habla y de los sonidos (notablemente trabajados en Los guantes mágicos), 
de Rejtman acumulan acciones encadenadas velozmente (y sin preocupación), alivianan los hechos que parecen igualarse, independientemente de su gravedad, restan profundidad psicológica a los personajes. Graciela Speranza ("Por un realismo idiota") entiende que la literatura de Rejtman forma parte de una renovada búsqueda realista en la literatura argentina. Este realismo no iría tras la mímesis ni el verosímil, sino que indagaría en el estatuto mismo de lo real, a partir de la fijación hiperrealista (Fogwill) o de la voracidad de la ficción (Aira). En el caso de Rejtman, se trataría de un realismo idiota. Speranza toma este término de Clément Rosset, para señalar una modalidad de captación individual, sin dobles, sin refracciones. Esa aprehensión sería idiota no en tanto ausencia de razón, sino como la percepción de la cualidad de unicidad y de singularidad del mundo. En Rejtman, tal idiocia estaría presente en la significación inmediata, en la superficialidad psicológica y sociológica, en la ausencia de pathos de las narraciones, en el azar que arrastra y enlaza a los personajes, en la velocidad de las acciones que deshilacha los códigos de representación de la ficción. En contra de tal percepción de idiocia habría que considerar, sin embargo, el humor sutil del narrador, además de la complejidad narrativa que se asoma en Tres cuentos (del que Speranza toma nota ["Tres cuentos. Martín Rejtman"]). Estrictamente en la perspectiva que propone Speranza, los libros de Rejtman se inscribirían en la misma tendencia de la literatura contemporánea argentina. Sus relatos serían lindantes con los textos de Aira y con los de Fogwill porque, cada uno con sus armas, rodean la relación de la literatura con lo real; una dirección que, en verdad, es recurrente en las artes contemporáneas (cf. Foster).

¿Podría utilizarse el mismo concepto para las películas de Martín Rejtman? ¿Hay una búsqueda de lo real en Rapado o en Los guantes mágicos en el mismo sentido que en Velcro y yo o en Tres cuentos? Si fuera así, sería redundante. La pantalla no puede sino ser realista; de hecho, los debates teóricos centrales del cine se han construido alrededor de este

la sencillez de la progresión narrativa y la utilización singular de la comedia -conectada tanto con ciertas comedias clásicas de Hollywood, como con los filmes de Aki Kaurismäki y con el humor de Nanni Moretti, y las sitcoms de los noventa-, esto es, la construcción de la imagen cinematográfica rejtmaniana tiene una potencia propia en la pantalla, en particular en relación con las producciones del mainstream del cine argentino de los años ochenta y parte de los noventa. Menos que autoría o estilo, es una forma novedosa de alimentar los poderes específicos del cine. 
tópico (Stam). Bien apunta Jacques Rancière que el cine, de acuerdo a su materia audiovisual, "muestra lo que muestra" (Las distancias del cine 18), y por lo tanto no puede emular la acción de la literatura. Por el contrario, crea distancias y contrariedades, quiere "emanciparse". De este modo, la literatura y el cine de Rejtman se despliegan en un espacio afín y con una estrategia común (la ruptura de códigos convencionales a partir de la acumulación, el humor, la superficialidad psicológica y dramática), aunque en sentidos cruzados. La literatura de Rejtman se compone, mayormente, de acciones y de situaciones encadenadas causalmente. No hay una problematización particular de la forma narrativa o de los diálogos. En el cine, en cambio, son principalmente el lenguaje (su ritmo, su textura) y la relación entre imágenes de objetos y acciones los procedimientos favoritos. ${ }^{18}$ Esto es, si la literatura alcanza una dimensión visual acompañando la velocidad de las acciones y de las superficies, las películas, entre otras cuestiones, enfatizan las acciones a partir de los modos lingüísticos, los ruidos, los ritmos. Las modalidades están cruzadas: la literatura se proyecta como una cámara; el cine se enfoca sobre los registros significantes. En lo profundo de estas dos construcciones diferenciadas, filmes y relatos confluyen en un mismo borde estético: indagar en el estatuto de la realidad explotando (en todos los sentidos de esta palabra) las posibilidades de la ficción.

A partir de este modo en que Rejtman amarra el lenguaje al cine es posible pensar el uso del habla en la película Sábado (2002, Juan Villegas). No porque este filme lo haga en el mismo sentido que en Rejtman, sino porque están planteadas a partir de su intervención en el cine: la repetición

18 Ese trabajo con el lenguaje, llevaría a una búsqueda de otro realismo, diferente de aquel de las películas de Trapero o Caetano. Dice Rejtman: "En Silvia Prieto el tema del lenguaje es más importante que el de la identidad. El gran problema de Silvia Prieto no es que haya otras personas como ella, sino otras que se llamen como ella. El nombre es lo que más importa [...]. Cuando se escucha hablar de otra manera no suena verdadero, cuando para mí lo cierto es que en la vida cotidiana se habla mucho más como en Silvia Prieto que como en una comedia televisiva del tipo Son amores. Para mí Silvia Prieto es una película realista y su código es absolutamente normal y cotidiano" (Fontana 85-86). En otra entrevista, Rejtman marca una diferencia sobre el uso del lenguaje en sus películas, desde la acción hacia un lenguaje-acción: "En Rapado lo que hacía era mirar personajes llevando a cabo acciones, básicamente. La cámara los miraba en sus acciones. En Silvia Prieto los mira en sus diálogos. Aunque todo diálogo también es una acción, y los diálogos están vistos, en este sentido, como acciones" (Peña, Generaciones 60/90 164). 
artificiosa y $\sin$ pathos de las frases hechas impactan sobre la verosimilitud de la ficción (Schwarzböck, "El enigma Silvia Prieto" 9). Este efecto (que operaría sobre una zona que desborda lo estrictamente literario y se abre hacia el lenguaje) ayuda a pensar también uno de los aspectos de Historias extraordinarias (2008, Mariano Llinás): la lectura continua en voz over durante más de cuatro horas, recurso que articula las líneas argumentativas del filme (y que, además, replantea el uso contemporáneo de la voz en el audiovisual [Noriega]). Se trata de un aspecto inusual para la trayectoria del cine: el cine trabaja -piensa, conceptualiza, narra- y tiene como recurso privilegiado cierta labor con las imágenes y los sonidos. La película de Llinás, recuperando un elemento residual de la cultura letrada y un recurso inicial del cine, reconvierte el registro de la lectura (la entonación, la pronunciación, las texturas propias de una voz que lee un texto escrito) en un aspecto medular de la propuesta del filme. ${ }^{19}$ Historias extraordinarias es la experiencia prolongada de quien lee (quien, además, agotado de tanto leer, pareciera pasarle la tarea a otras voces sin muchas explicaciones). Las imágenes se acoplan como si estuvieran en un segundo plano de la narración, como sucede cuando se incorpora una voz over que solapa los diálogos, aunque en este caso, llevada a un extremo. Y aquí encuentra un camino realmente innovador que no tendría si Llinás hubiera escrito diálogos convencionales. Historias extraordinarias podría haber sido una novela, de acuerdo con su preferencia por la palabra leída y por el modo de desarrollar los episodios, pero, en cambio, elige una forma extraña y crítica de ligar la palabra y la imagen.

El desarrollo del cine contemporáneo demanda considerar la complejidad de vínculos orgánicos y de acciones múltiples. De acuerdo con esto, puede advertirse que los lazos entre el cine y la literatura tienen necesariamente direcciones diversificadas. Hay, por un lado, una reconversión de un espacio sociocultural confluyente y desestructurado, en el que las operaciones de los cineastas y de los escritores se desarrollan en un territorio común y menos segmentado, aunque estas acciones frecuentemente

19 Según lo señalan Gaudreault y Jost, en los primeros años del cine, cuando todavía no estaba desarrollado un lenguaje cinematográfico (y antes de que aparecieran los intertítulos), las proyecciones estaban acompañadas por las palabras de un presentador. Este, mientras se sucedían las imágenes, leía pasajes pautados que permitían comprender los hiatos narrativos de una escena o de una acción a la otra. La idea del presentador-lector suponía la idea de un público no letrado y de cierta precariedad del cine como lenguaje. 
potencien producciones o figuras particulares. Por el lado estético los cruces se amplían más aún; el vínculo entre ambas zonas se afirma cuanto las operaciones parecen, a la vez, unirse y contradecirse, en tanto funcionan a partir de una mistura. Se trata de una sujeción que funciona incorporando lo ajeno y alterando lo propio. A partir de esta sociedad, complementaria y paradójica, se alimentan y se afirman los lazos del cine y la literatura.

\section{Obras citadas}

Aguilar, Gonzalo. Otros mundos. Un ensayo sobre el nuevo cine

argentino. Buenos Aires: Santiago Arcos, 2010. Impreso.

Aira, César. La guerra de los gimnasios. Buenos Aires: Emecé, 1993. Impreso.

Aira, César. La prueba. Buenos Aires: Grupo Editor Latinoamericano, 1992. Impreso.

Andermann, Jens. El nuevo cine argentino. Buenos Aires: Paidós, 2015. Impreso.

Bernini, Emilio, Domin Choi y Daniela Goggi. "Los no realistas. Conversación con Ezequiel Acuña, Diego Lerman y Juan Villegas". Kilómetro 1115 (Buenos Aires, noviembre de 2004): 163-169. Impreso.

Bottone, Mireya. La literatura argentina y el cine. Santa Fe: Universidad Nacional del Litoral, 1964. Impreso.

Casas, Fabián. Ocio seguido de Veteranos del pánico. Buenos Aires: Santiago Arcos, 2008. Impreso.

Cernadas, Jorge. "Notas sobre la desintegración del consenso antiperonista en el campo intelectual: Sur, 1955-1960". Cultura y política en los años '60. Coord. Enrique Oteiza. Buenos Aires: Instituto de Investigaciones "Gino Germani", Facultad de Ciencias Sociales, Universidad Nacional de Rosario, 1997. 133-149. Impreso.

Contreras, Sandra. Las vueltas de César Aira. Rosario: Beatriz Viterbo, 2002. Impreso.

Couselo, Jorge. "Literatura argentina y cine nacional". Capítulo. La historia de la literatura argentina. Buenos Aires: CEAL, 1981. 601-624. Impreso.

Di Benedetto, Antonio. Los suicidas. Buenos Aires: CEAL, 1982. Impreso.

España, Claudio, dir. Cine argentino. Modernidad y vanguardias 19571983. Buenos Aires: Fondo Nacional de las Artes, 2005. Impreso.

España, Claudio. "Emergencia y tensiones en el cine argentino de los años cincuenta". Nuevo Texto Crítico X (1997): 45-73. Impreso.

Fontana, Patricio. "Martín Rejtman. Una mirada sin nostalgias". Milpalabras 4 (Buenos Aires, primavera de 2002): 81-88. Impreso.

Foster, Hal. El retorno de lo real. La vanguardia a finales de siglo. Madrid: Akal, 2001. Impreso.

Gaudreault, André y Francois Jost. El relato cinematográfico. Cine y narratología. Barcelona: Paidós, 1995. Impreso. 
Guerschuny, Hernán y Pablo Udenio. "Cinéfilo es una palabra rara". Haciendo Cine 5 (Buenos Aires, octubre de 1996): 32-37. Impreso.

Kohan, Martín. Ciencias Morales. Barcelona: Anagrama, 2007. Impreso.

Malba.cine. "La guerra de los gimnasios". N.p., n.d. http://intranet.malba.org.ar/ web/cine_pelicula.php?id=1255\&subseccion=peliculas_proyectadas. Web.

Noriega, Gustavo. "La película del X Bafici: Historias extraordinarias, de Mariano Llinás". elamante.com (23 de marzo de 2010). http://web.archive.org/ web/20111112031944/http://www.elamante.com/content/view/1493/1/. Web.

Oubiña, David. Manuel Antín. Buenos Aires: CEAL, 1994. Impreso.

Peña, Fernando M., comp. Generaciones 60/90. Cine argentino independiente. Buenos Aires: MALBA, 2003. Impreso.

Peña, Fernando M. Leopoldo Torre Nilsson. Buenos Aires: CEAL, 1993. Impreso.

Posadas, Abel. "La caída de los estudios. ¿Sólo el fin de una industria?". Cine argentino. La otra historia. Comp. Sergio

Wolf. Buenos Aires: Letra Buena, 1992. 217-241. Impreso.

Rancière, Jacques. El reparto de lo sensible. Estética y política. Santiago: LOM, 2010. Impreso.

Rancière, Jacques. La fábula cinematográfica. Barcelona: Paidós, 2005. Impreso.

Rancière, Jacques. Las distancias del cine. Buenos Aires: Manantial, 2012. Impreso.

Rancière, Jacques. Política de la literatura. Buenos

Aires: Libros del Zorzal, 2011. Impreso.

Rapallo, Armando. Fernando Ayala. Buenos Aires: CEAL, 1993. Impreso.

Rejtman, Martín. Literatura y otros cuentos. Buenos Aires: Interzona, 2005. Impreso.

Rejtman, Martín. Rapado. Buenos Aires: Interzona, 2005. Impreso.

Rejtman, Martín. Silvia Prieto. Buenos Aires: Norma, 1999. Impreso.

Rejtman, Martín. Velcro y yo. Buenos Aires: Planeta, 1996. Impreso.

Rejtman, Martín. Tres cuentos. Buenos Aires: Mondadori, 2012. Impreso.

Sánchez Noriega, José Luis. De la literatura al cine. Teoría y análisis de la adaptación. Barcelona: Paidós, 2000. Impreso.

Schwarzböck, Silvia. "El enigma Silvia Prieto". El Amante 87 (Buenos Aires, junio de 1999): 9. Impreso.

Schwarzböck, Silvia. "Los no realistas". El Amante 115

(Buenos Aires, noviembre de 2001): 9. Impreso.

Speranza, Graciela. "Por un realismo idiota". Otra Parte 8 (Buenos

Aires, otoño de 2006). http://revistaotraparte.com $/ \mathrm{n} \% \mathrm{C}_{2} \% \mathrm{BA}$ -

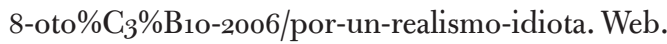


Speranza, Graciela. "Tres cuentos. Martín Rejtman". Otra Parte semanal (Buenos Aires, 4 de abril de 2013). http://revistaotraparte. com/semanal/literatura-argentina/tres-cuentos/. Web.

Terán, Oscar. Nuestros años sesentas. La formación de la nueva izquierda intelectual en Argentina 1956-1966. Buenos Aires: Puntosur, 1991. Impreso.

Wolf, Sergio. Cine/Literatura. Ritos de pasaje. Buenos Aires: Paidós, 2001. Impreso.

Zangrandi, Marcos. "Imágenes en el abismo: Antín, Cortázar e Intimidad de los parques". Revista Chilena de Literatura 92 (2016): 251-257. Impreso. 